\title{
Direct Shear Behavior of Nanometer Magnesia Reinforced Cement Soil with 28d Age
}

\author{
Shuai Zhang ${ }^{1}$, Wei Wang ${ }^{*}{ }^{1,2}$, Xinjiang Song ${ }^{3}$, Xuchao $\mathrm{Chi}^{2,4}$ and Tinghao $\mathrm{Lu}^{1}$ \\ ${ }^{I}$ Key Laboratory of Ministry of Education for Geomechanics and Embankment Engineering, Hohai University, Nanjing, \\ 210092, China \\ ${ }^{2}$ School of Civil Engineering, Shaoxing University, Shaoxing, 312000, China \\ ${ }^{3}$ Huaihe River Committing Ministry of Water Resources, Bengbu, 233000, China \\ ${ }^{4}$ Melbourne School of Design, Melbourne University, Victoria, 3010, Australia
}

\begin{abstract}
In order to properly understand the modification effects of nanometer magnesia additive on cement soil's mechanical performance, a consolidated quick shear laboratory test on nano-magnesium-modified cement-soil (NmCS) sample with different mixing ratio at 28-day age was conducted. Eight kinds' of nanometer magnesia additives with mixing ratios ranging from $0 \%$ to $3 \%$ were designed to be used in the test. The result shows that: (1) shear stressdisplacement curves of all samples consisted of three distinct stages with brittle failure. Moreover, (2) as the nanometer magnesia mixing ratio increased, the NmCS shear strength also showed an increase at first, followed by a decrease, and the shear strength reached the maximum with the mixing ratio of $1 \%$. (3)In addition, both the friction angle and cohesive force were fluctuating and had a concave and convex shape respectively and (4) with greater deformation resistance, the shear displacement of $\mathrm{NmCS}$ was significantly less than the ordinary cement soil in the shear failure process. Finally, according to the test results, the micro-mechanism of NmCS mechanical performance was analyzed from the perspective of cement hydration and particle interaction.
\end{abstract}

Keywords: Cement stabilized soil, Nanometer magnesia, Mixing ratio, Shear strength.

\section{INTRODUCTION}

With obvious comprehensive benefits of the application of foundation treatment technology, cement stabilized soil has been widely applied to the practical engineering construction such as foundation reinforcement of various types of buildings, roads, railways, airports, and etc.; building envelopes and water-resisting curtains of the excavation process; foundation reinforcement and seepage of various large water conservancy dams; and road base material and impermeable lining material. In the engineering practice, however, there are some problems such as cement soil strength is not high with large deformation of composite foundation in the later process, which restricts the further application of this technology $[1,2]$. It is a very important study to find out an admixture with high modification effect to improve the cement soil's strength.

Currently, silica ash, fly ash and other common ultra-fine mineral powder have been widely used to increase the performance of concrete, cement soil and other cementbased materials, which have been utilized in the field of engineering. Scientific research shows that when the substances are processed below to $100 \mathrm{~nm}$ size, extraordinary properties will be produced which are different not only

*Address correspondence to this author at the School of Civil Engineering, Shaoxing University, Huancheng West Road, Shaoxing, 312000, China; Tel: 1836712859; E-mail: wangwells@qq.com from the microscopic atoms and molecules, but also from the macroscopic perspective. This excellent feature is called "nano effect" [3-7]. With the popularity of nano products and people's recognition of its performance and quality, nano materials have been well developed and industrialized production has been started for some nano materials. Nano mineral powder particle size varies between $1 \sim 100 \mathrm{~nm}$ with outstanding features such as large specific surface area and unsaturated surface atoms coordination. Therefore, mixing nano mineral powder with finer particles and larger specific surface area and higher activity into cement soil is being explored [8-11]. Nano-MgO is a new high-performance fine inorganic material with optical, electrical, magnetic and chemical properties which has been widely applied to the field of electronics, catalysis, ceramics, antibacterial and buildings $[12,13]$.

In this paper, industrialized production of nano- $\mathrm{MgO}$ was taken as the cement soil admixture to study its modification effect on the cement soil, to explore the shear strength and deformation of nano-magnesium-modified cement-soil (hereinafter referred to as: "NmCS"), analyze and evaluate the nano-MgO modification effect on cement soil. Thus the research and exploration was carried out for the application in engineering practice.

\section{MATERIALS AND METHODOLOGY}

Clay soils with low liquid which are widely distributed in the eastern coastal area of China were taken as the test soil, 
and samples were taken from Qingliangshan, Nanjing City, Jiangsu Province, with $30 \%$ moisture content, $1.9 \mathrm{~g} / \mathrm{cm}^{3}$ wet density, 2.69 specific gravity of soil particles, $43 \%$ liquid limit, 20\% plastic limit, and 23 plasticity index; with $11.5 \mathrm{kPa}$ cohesion and $15.2^{\circ}$ friction angle in the consolidation quick direct shear process.

P.C 32.5\# Composite Portland Cement produced by Nanjing Conch Cement Co., Ltd., and Nano-MgO produced by Aladdin Industrial Corporation were used in this experiment.

The soil samples were prepared by drying and crushing, and sifting over a diameter of $2 \mathrm{~mm}$ sieve. The test sample was prepared by the designed ratio. In the preparation process, soil samples, cement and Nano-MgO with specified amount were sealed in a closed container, stirring for 8 minutes until evenly mixed, and a water kettle was used to uniformly spray the soil, and stirring of the mixture was continued evenly until the required moisture and humidity were achieved. The wet soil moisture content was $30 \%$ and ratio between cement and wet soil quality was $10 \%$. Compared with the soil cement, eight kinds of Nano-MgO mixing ratios were taken as $0 \%, 0.25 \%, 0.5 \%, 1.0 \%, 1.5 \%$, $2.0 \%, 2.5 \%$ and $3.0 \%$.

Shear samples were of $6.18 \mathrm{~cm}$ diameter, $2 \mathrm{~cm}$ height, and $(1.98 \pm 0.02) \mathrm{g} / \mathrm{cm}^{3}$ sample density. Four normal stresses were considered in the direct shear test. In order to prevent the sample damage, five samples were prepared in each group including a spare; being cured to $28 \mathrm{~d}$ age in the curing box, followed by the consolidated quick shear test .

During the test, the sample was consolidated initially and shear test was conducted after $24 \mathrm{~h}$. In the shearing process, the fixed pin was pulled out and immediately sheared with $0.8 \mathrm{~mm} / \mathrm{min}$ shear rate. The samples with shear failure were obtained in $4 \mathrm{~min} \sim 6 \mathrm{~min}$. Before the shearing failure, the shear stress shown on the instrument was recorded per $0.2 \mathrm{~mm}$ shear displacement; while after the sample failure, it was per $0.1 \mathrm{~mm}$ shear displacement. Shearing was continued after samples' failure with peak shearing stress until the instruments reading became stable.

\section{RESULTS AND ANALYSIS}

\subsection{Failure Characteristics}

In the consolidation quick direct shear process of nano$\mathrm{MgO}$ cement soil with different mixing ratios, the shear displacements were less than $1 \mathrm{~mm}$ with brittle failure. Failure processes are basically the same for each sample. At $28 \mathrm{~d}$ age with mixing ratio $\mathrm{a}_{\mathrm{w}}=1.0 \%$, the relations between shear stress $\tau$ and shear displacement $\Delta$ of NmCS are shown in Fig. (1). There are 3 distinct phases included in the shearing process:

Phase (1): Before shear failure, with increase in the shear displacement, the shear stress $\tau$ showed a linear increase. When the shear stress $\tau \leq 0.7 \tau_{\max }$ ( $\tau_{\max }$ is the peak shear stress), $\tau-\Delta$ relations had linear variation. When the shear stress $\tau>0.7 \tau$ max, displacement growth rate became

higher than the stress growth rate, and shear stress produced plastic deformation until stress-deformation curve reached the peak point.
Phase (2): During shear failure, when the data shown on the instrument reached the maximum, the samples were suddenly sheared broken and the data instantly decreased to a minimum. NmCS samples showed brittle failure under different normal stress.

Phase (3): After shear failure, with continued increase in the shear displacement $\Delta$, the shear stress $\tau$ still increased. After a period of increase, the shear stress became stable while the residual shear stress became less than the peak shear stress.

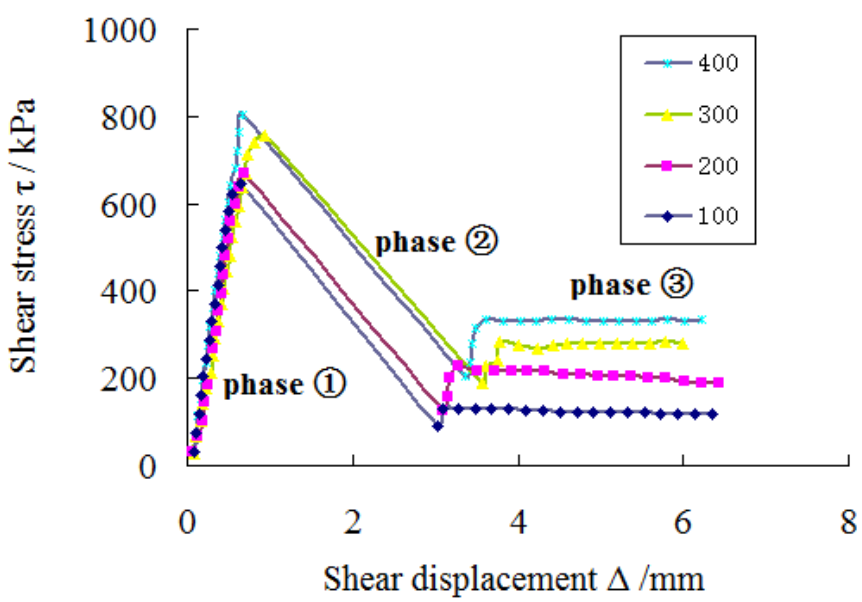

Fig. (1). Shear stress-displacement curves of NmCS.

\subsection{Shear Strength}

The peak stress in the $\tau-\Delta$ curves is taken as the shear strength. The experimental results of shear strength of each NmCS sample are shown in Table 1.

Table 1. Investigated shear strength of NmCS / $\mathrm{kPa}$.

\begin{tabular}{|c|c|c|c|c|}
\hline $\mathbf{a}_{\mathbf{w}}$ & \multicolumn{4}{|c|}{ Normal Stress/ kPa } \\
\hline$/(\mathbf{\%})$ & $\mathbf{1 0 0}$ & $\mathbf{2 0 0}$ & $\mathbf{3 0 0}$ & $\mathbf{4 0 0}$ \\
\hline \hline 0.00 & 339 & 438 & 547 & 638 \\
\hline 0.25 & 370 & 505 & 573 & 688 \\
\hline 0.50 & 409 & 541 & 642 & 721 \\
\hline 1.00 & 646 & 714 & 757 & 803 \\
\hline 1.50 & 539 & 624 & 745 & 777 \\
\hline 2.00 & 452 & 569 & 647 & 720 \\
\hline 2.50 & 434 & 497 & 574 & 686 \\
\hline 3.00 & 332 & 463 & 568 & 661 \\
\hline
\end{tabular}

As can be seen from Table 1, under different normal stresses, the shear strength variation of the NmCS was roughly the same, and the shear strength $\tau$ first increased and then decreased with the Nano-MgO mixing ratio aw. When $\mathrm{a}_{\mathrm{w}}=1.0 \%$, the NmCS shear strength maximum can reach to $646 \mathrm{kPa}, 714 \mathrm{kPa}, 757 \mathrm{kPa}$ and $803 \mathrm{kPa}$ respectively under different normal stress, which are 1.90 times, 1.63 times, 1.38 times and 1.26 times that of the ordinary cement soil in the same period. With continuous increase in the mixing ratio, 
NmCS shear strength showed continuous decrease, but its strength value was still greater than the strength of ordinary cement soil. According to Table 1, the fitting curves of the shear strength of NmCS were obtained under different normal stress by the following fitting equation:

$$
\left\{\begin{array}{c}
\tau_{100}=33.7 a_{\mathrm{w}}^{3}-255.0 a_{\mathrm{w}}^{2}+72.5 a_{\mathrm{w}}+300.0 \\
\tau_{200}=46.6 a_{w}^{3}-298.7 a_{w}^{2}+491.5 a_{w}+414.2 \\
\tau_{300}=41.8 a_{w}^{3}-268.8 a_{w}^{2}+444.4 a_{w}+513.0 \\
\tau_{400}=30.8 a_{w}^{3}-195.8 a_{w}^{2}+320.6 a_{w}+626.8
\end{array}\right.
$$

In the equation, $\tau_{100}, \tau_{200}, \tau_{300}$, and $\tau_{400}$ are the $\mathrm{NmCS}$ shear strength under normal stress $100 \mathrm{kPa}, 200 \mathrm{kPa}, 300 \mathrm{kPa}$ and $400 \mathrm{kPa}$ respectively.

\subsection{Cohesion and Friction Angle}

With different nano-MgO mixing ratios, the shear strength and the normal stress of NmCS samples showed a linear relation which complies with Moore Coulomb criterion. The measured data and fitting data with three typical mixing ratios are shown in Fig. (2).

$\tau_{f}=c+\sigma \tan \varphi$

In the equation, $c$ is the cohesion and $\varphi$ is the friction angle.

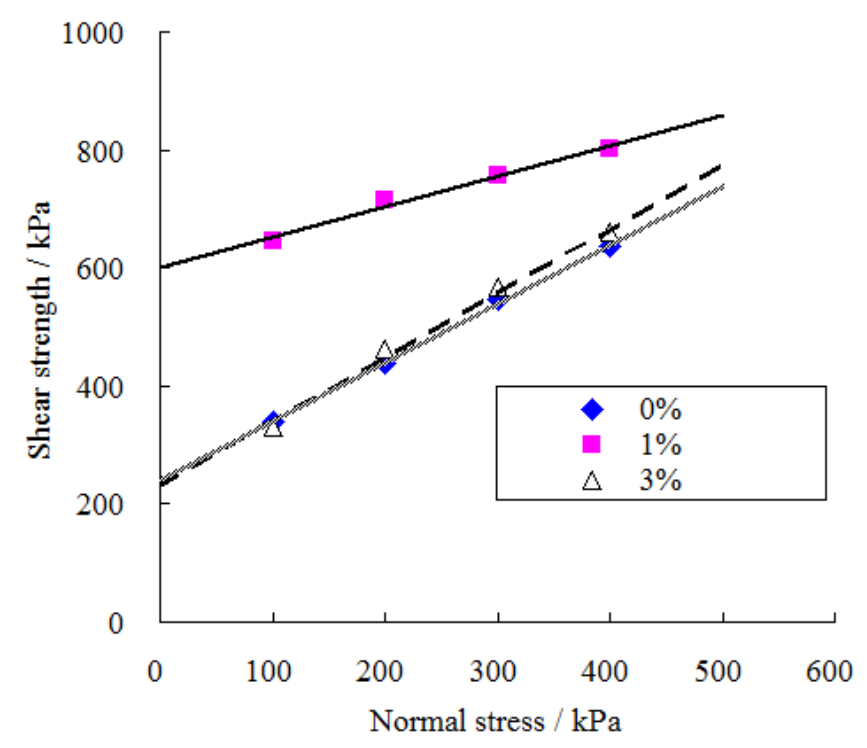

Fig. (2). Relations between Normal Stress and Shear Strength.

According to equation (2) and Table 1, $\varphi$ and $c$ of NmCS were calculated and curves were drawn as shown in Figs. (3, 4). As can be seen from Figs. $(3,4)$, with increase in nano$\mathrm{MgO}$ mixing ration aw, the friction angle $\varphi$ and cohesion $\mathrm{c}$ showed fluctuating variation with concave and convex shape respectively. When aw $=1.0 \%, \varphi$ and $\mathrm{c}$ were up to their maximum value and the minimum value respectively.

\subsection{Deformation Characteristics}

It was found that $\mathrm{NmCS}$ exhibited a better deformation resistance than ordinary cement soil. According to phase (1) in Fig. (1), by taking aw as $0 \%$ and $1.0 \%$ and shear displacement of $0.4 \mathrm{~mm}$ for example; the shear stress are shown in Table 2. As can be seen from Table 2, NmCS had greater deformation resistance with same shear displacement. The shear stress it can withstand is significantly higher than the ordinary cement soil with the same displacement, when normal stresses are $100 \mathrm{kPa}, 200 \mathrm{kPa}, 300 \mathrm{kPa}$ and $400 \mathrm{kPa}$. The shear stress of NmCS was 1.9 times, 1.5 times, 1.2 times, 1.2 times that of the normal cement soil.

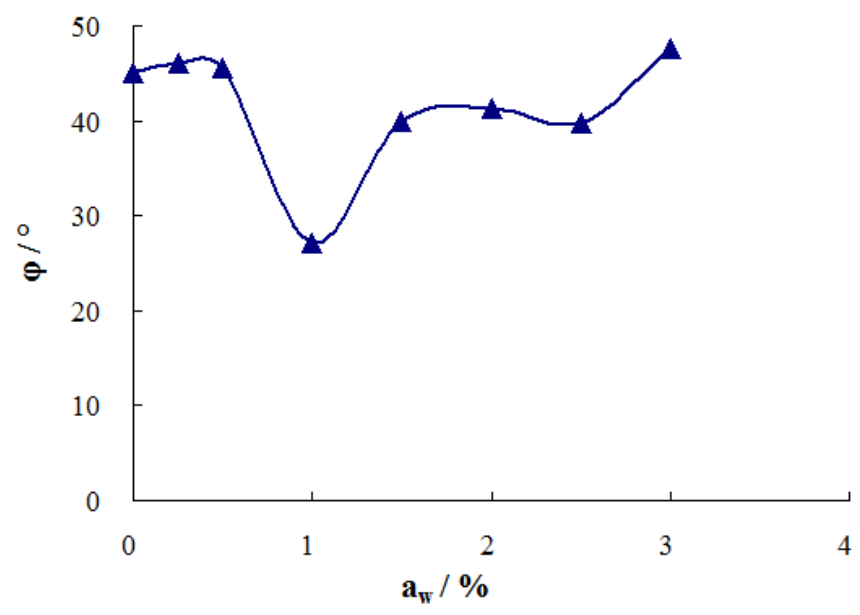

Fig. (3). Friction Angles of NmCS with Different nano-MgO Ratio.

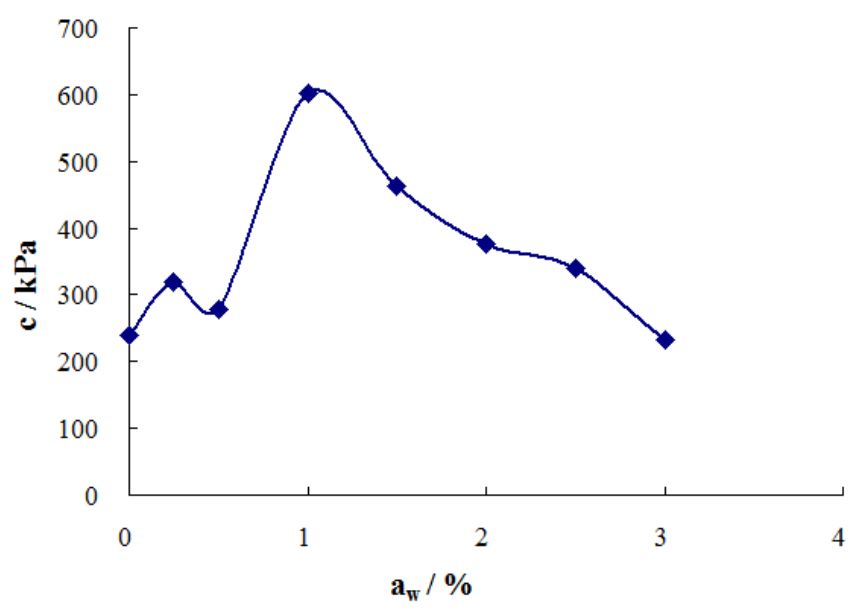

Fig. (4). Cohesion of NmCS with Different nano-MgO Ratio.

Table 2. Shear stress at $0.4 \mathrm{~mm}$ shear displacement $/ \mathrm{kPa}$.

\begin{tabular}{|c|c|c|c|c|}
\hline $\mathbf{a}_{\mathbf{w}}$ & \multicolumn{4}{|c|}{ Normal Stress/ kPa } \\
\hline$/(\mathbf{\%})$ & $\mathbf{1 0 0}$ & $\mathbf{2 0 0}$ & $\mathbf{3 0 0}$ & $\mathbf{4 0 0}$ \\
\hline \hline 0.00 & 274 & 320 & 390 & 434 \\
\hline 1.00 & 512 & 468 & 464 & 520 \\
\hline
\end{tabular}

If applied to cement mixing pile, NmCS pile with nano$\mathrm{MgO}$ admixture under the action of transverse shear force produces smaller shear displacement. It is more stable which can greatly improve critical force of the compression bar compared with the ordinary cement pile. Its strength is higher than NmCS pile. Therefore, it has much wider application than ordinary cement pile.

Based on the above analysis, with more mechanical properties improvement, $\mathrm{NmCS}$ with $1 \%$ nano-MgO mixing ratio is considered as the best ratio. 


\section{NmCS CURING MECHANISM ANALYSIS}

$\mathrm{MgO}$ is an alkaline oxide which absorbs moisture and carbon dioxide easily to produce basic magnesium carbonate when exposed to air. $\mathrm{MgO}$ has hygroscopicity with a certain relation to the size of the surface area, suggesting that the larger the surface area, the higher the hygroscopicity. Therefore, the Nanoscale $\mathrm{MgO}$ surface has superhydrophilic property. Water adsorbed by surface can be dissociated by the reaction which makes it easy to form chemically adsorbed water, forming a physically adsorbed layer. Thus, nano- $\mathrm{MgO}$ mixed in the cement can quickly adsorb $\mathrm{Ca}^{2+}$ ions in the liquid phase to form small crystalline state $\mathrm{Ca}(\mathrm{OH})_{2}$ to accelerate the hydration rate of $\mathrm{C} 3 \mathrm{~S}$, which can improve the rate of hydration of cement particles to form a more compact calcium silicate hydrate gel structure. Meanwhile, NmCS has a more uniform and dense microstructure. Nano-MgO filling affect is an important factor in improving cement-stabilized soil's microstructure. Nano-MgO mixed in cement paste is used to fill the pores of hydration products to make the cement structure denser [1].

To conclude, nano-MgO is characterized by the properties of small particle, large specific surface area and is super-hydrophilic. When mixed with soil, it can be adsorbed on the soil surface, thus becoming the core of calcium silicate hydrate gel produced by normal cement hydration, so that the calcium silicate hydrate gel can be preferably knotted together with compact structure. The nano-MgO mixed in the cement soil also has similar filling effect on the cement soil. It can reduce the number of pores and refine the soil cement pore size. The larger soil aggregates can be further combined to close the gap between each soil group and join together to overall improve the microstructure of cement to enhance their strength [9]. Thus, NmCS's strength will significantly be improved with a suitable mixing ratio.

\section{RESULTS AND DISCUSSION}

According to the quick direct shear test of NmCS with different mixing ratios with $28 \mathrm{~d}$ age, preliminary conclusions are as follows:

(1) When the nano- $\mathrm{MgO}$ mixing ratio $\mathrm{aw}=1 \%$ under the normal stress of $100 \mathrm{kPa}, 200 \mathrm{kPa}, 300 \mathrm{kPa}$ and $400 \mathrm{kPa}$, the shear strength of NmCS was 1.90 times, 1.63 times, 1.38 times and 1.26 times that of the ordinary cement soil, respectively;

(2) When the normal stress was $100 \mathrm{kPa}, 200 \mathrm{kPa}, 300 \mathrm{kPa}$ and $400 \mathrm{kPa}$ and with shear displacement of $0.4 \mathrm{~mm}$, NmCS shear stress was 1.9 times, 1.5 times, 1.2 times, 1.2 times than that of ordinary cement soil, respectively;

(3) When nano-MgO mixing ratio was relatively small, the growth rate of NmCS strength was relatively increased, however, when mixing ratio exceeded to a certain value, the growth rate began to decline.

Although nano- $\mathrm{MgO}$ as admixture showed excellent enhancement effect in this study, there are still further researches need to be further examined:

Clay soils with low liquid as the test soil samples were taken from Qingliangshan, Nanjing City,
Jiangsu Province. With increase in the the nanoMgO's mixing ratio, the NmCS shear strength of each vertical stress increased first then decreased and again increased. This variation mechanism may be varying with different original soil components which need further experimental and theoretical exploration.

(2) Composite Portland cement taken in the experiment was green building materials which contains mixed material, with stable strength in the early and late stage having low heat of hydration. It is an economical cement which is suitable for general industrial and civil construction application. The total mixing ratio of the hybrid material by mass ratio ranges from $20 \% \sim 50 \%$ with not very high Portland cement clinker content, which may result in creating limited effect of nano-MgO on the soil cement. This is different from the ordinary Portland cement used in the cement soil study conducted by Zhu [8] and Wang [9]. Later, ordinary Portland cement will be taken for the comparison to explore the relations between the strength improvement and environment protection.

(3) NmCS strength depends on the structure of the gel material and connection between the gel material and soil particles. Nano-MgO admixture can enhance cement gel material structure to reduce cement soil porosity and improve connection between the gel material and soil particles. Interactions between nano$\mathrm{MgO}$ and soil remain to be explored further. With continuous advances in Nanotechnology, comprehensive benefits of nano- $\mathrm{MgO}$ application to soil cement and other cement-based materials will provide a broad space for the transformation of traditional industries.

\section{CONFLICT OF INTEREST}

The authors confirm that this article content has no conflict of interest.

\section{ACKNOWLEDGEMENTS}

This research was supported by the National Natural Science Foundation of China (NO. 41202222), the Nature Science Foundation of Anhui Province (1408085ME99), and the Key Laboratory of Ministry of Education for Geomechanics and Embankment Engineering, Hohai University (GH201102), the Pandeng Foundation for academic leader of the subjects of Zhejiang Province University (NO. pd2013387).

\section{REFERENCES}

[1] W. J. Wang, and X. R. Zhu, "Study on strength property of Nanometer silica fume reinforced cemented soil and reinforcement mechanism", Rock and Soil Mechanics, vol. 25, pp. 922-26, 2004.

[2] Y.X. Tang, H. L. Liu, and W. Zhu, "Study on engineering properties of cement-stabilized soil", Chinese Journal of Geotechnical Engineering, vol. 22, pp. 549-54, 2000.

[3] M. Zhang and H. Li, "Pore structure and chloride permeability of concrete containing nano-particles for pavement", Construction and Building Materials, vol. 25, pp. 608-16, 2011.

[4] M.R. Alaa, E. S. Hosam and A. F. Shaheen, "Effect of silica fume and slag on compressive strength and abrasion resistance of HVFA concrete", International Journal of Concrete Structures and Materials, vol. 8, pp. 69-81, 2012. 
[5] E. Hammel, X. Tang, M. Trampert, T. Schmitt, K. Mauthner, and A. Eder, "Carbon nanofiber for composite applications", Carbon, vol. 42, pp. 1153, 2004

[6] M. S. Konsta Gdoutos, S. Metaxa, and S. P. Shah, "Multiscale mechanical and fracture characteristics and early-age strain capacity of high performance carbon Nanotube/cement Nanocomposites", Cement Concrete Composite, vol. 32, pp. 110$5,2010$.

[7] S.Y. Zhang, Y. F. Fan, H. Y. Luan, and Y. Chen, "Effect of disperse condition of Nano-clay on behavior cement paste", Journal of Building Materials, vol. 16, pp. 197-202, 2013.

[8] X. R. Zhu and L. F. Wang and F. T. Ding, "Study on engineering properties of Nanometer silica and cement-stabilized soil", Geotechnical Engineering Technique, vol. 4, pp. 187-93, 2003.

[9] W. J. Wang, X. R. Zhu and P. F. Fang, "Analysis on reinforcement mechanism of Nanometer silica fume reinforced cemented clay", Journal of Zhejiang University (Engineering Science), vol. 39, pp. 148-53, 2005.

[10] M. S. Morsy, S. H. Alsayed and M. Aqel, "Hybrid effect of carbon Nanotube and Nano-clay on physico-mechanical properties of cement mortar", Construction and Building Materials, vol. 25, pp. 145-9, 2011.

[11] M. S. Morsy, S. H. Alsayed and M. Aqel, "Effect of Nano-clay on mechanical properties and microstructure of ordinary Portland cement mortar", International Journal of Civil \& Environmental Engineering, vol. 10, pp. 23-27, 2010.

[12] Z. H. Gao, H. F. Liu, Q. H. Pan, L. and J. Hu, "Study on the surface modification of Nano-sized $\mathrm{MgO}$ powder", Inorganic Chemicals Industry, vol. 40, pp. 28-30, 2008.

[13] J. T. Jiu, L. T. Li, Y. Ge, S. R. Zhang, F. Tu, Z. R. Hua, and L. Ni, "The preparation of MgO nanoparticles protected by polymer", Chinese Journal of Inorganic Chemistry, vol. 17, pp. 361-5, 2001.

Received: September 10, 2014

Revised: November 5, 2014

Accepted: November 5, 2014

(C) Zhang et al.; Licensee Bentham Open.

This is an open access article licensed under the terms of the Creative Commons Attribution Non-Commercial License (http://creativecommons.org/licenses/ by-nc/4.0/) which permits unrestricted, non-commercial use, distribution and reproduction in any medium, provided the work is properly cited. 